\title{
Annual Summary of Vital Statistics: 2009
}

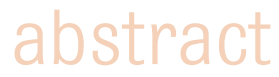

The number of births in the United States decreased by 3\% between 2008 and 2009 to 4130665 births. The general fertility rate also declined $3 \%$ to 66.7 per 1000 women. The teenage birth rate fell $6 \%$ to 39.1 per 1000. Birth rates also declined for women 20 to 39 years and for all 5-year groups, but the rate for women 40 to 44 years continued to rise. The percentage of all births to unmarried women increased to $41.0 \%$ in 2009 , up from $40.6 \%$ in 2008. In $2009,32.9 \%$ of all births occurred by cesarean delivery, continuing its rise. The 2009 preterm birth rate declined for the third year in a row to $12.18 \%$. The lowbirth-weight rate was unchanged in 2009 at $8.16 \%$. Both twin and triplet and higher order birth rates increased. The infant mortality rate was 6.42 infant deaths per 1000 live births in 2009. The rate is significantly lower than the rate of 6.61 in 2008. Linked birth and infant death data from 2007 showed that non-Hispanic black infants continued to have much higher mortality rates than non-Hispanic white and Hispanic infants. Life expectancy at birth was 78.2 years in 2009. Crude death rates for children and adolescents aged 1 to 19 years decreased by $6.5 \%$ between 2008 and 2009. Unintentional injuries and homicide, the first and second leading causes of death jointly accounted for $48.6 \%$ of all deaths to children and adolescents in 2009. Pediatrics 2012;129:338-348
AUTHORS: Kenneth D. Kochanek, MA, ${ }^{a}$ Sharon E. Kirmeyer, PhD, a Joyce A. Martin, MPH, a Donna M. Strobino, PhD, , and Bernard Guyer, MD, MPH ${ }^{\mathrm{b}}$

aDivision of Vital Statistics, National Center for Health Statistics, Centers for Disease Control and Prevention, Hyattsville,

Maryland; and ${ }^{b}$ Department of Population and Family Health

Sciences, Johns Hopkins Bloomberg School of Public Health, Baltimore, Maryland

KEY WORDS

birth, death, teenaged fertility, infant mortality, low birth weight, mortality, multiple births, cesarean rate, vital statistics, International Classification of Diseases, Tenth Revision, revised certificates

\section{ABBREVIATIONS}

CDC-Centers of Disease Control and Prevention

IMR-infant mortality rate

LBW-low birth weight

NCHS - National Center for Health Statistics

NMR - neonatal mortality rate

OMB-Office of Management and Budget

www.pediatrics.org/cgi/doi/10.1542/peds.2011-3435

doi:10.1542/peds.2011-3435

Accepted for publication Nov 23, 2011

Address correspondence to Kenneth D. Kochanek, MA, Centers for Disease Control and Prevention, National Center for Health Statistics, 3311 Toledo Rd, Room 7318, Hyattsville, MD 20782. E-mail: kdk2@cdc.gov

PEDIATRICS (ISSN Numbers: Print, 0031-4005; Online, 1098-4275). Copyright (C) 2012 by the American Academy of Pediatrics FINANGIAL DISCLOSURE: The authors have indicated that they have no financial relationship to this article to disclose. 
This annual article is a long-standing feature in Pediatrics and provides a summary of the most current vital statistics data for the United States. We also include a special feature this year on the upcoming release of selected new items from the 2003 US Certificate of Live Birth.

\section{METHODS}

The data presented in this report were obtained from vital statistics records: birth certificates and death certificates for residents in all US states and the District of Columbia. Birth and death data for 2008 and birth data for 2009 are final. Mortality data for 2009 are preliminary and based on $>96 \%$ of records. More complete descriptions of vital statistics data systems are available elsewhere. ${ }^{1-7}$

Current vital statistics patterns and recent trends through 2008 and 2009 are presented according to age, race, and Hispanic origin, and other birth and death characteristics, as well. Hispanic origin and race are collected as separate items in vital records. Persons of Hispanic origin may be of any race. A number of reporting areas allow for multiple-race categories on birth and death certificates. However, until all areas revise their certificates to reflect updated reporting standards for race, ${ }^{8}$ multiple-race data are "bridged" back to single-race categories. $2,4,9,10$ For birth data, mother's marital status was reported directly in all reporting areas but New York State and New York City in 2008 and 2009. Details about the reporting of marital status in New York and editing methods and imputations as applied to other items on the birth certificate are presented in publications of the National Center for Health Statistics (NCHS). ${ }^{11}$

Cause-of-death statistics in this report are based solely on the underlying cause of death compiled in accordance with the International Classification of
Diseases, 10th Revision (ICD-10).12 The underlying cause of death is defined as "(a) the disease or injury which initiated the train of morbid events leading directly to death, or (b) the circumstances of the accident or violence which produced the fatal injury."12 For certain causes of death, such as unintentional injuries, homicides, suicides, drug-induced deaths, and sudden infant death syndrome, preliminary data may show lower numbers of death relative to final data for the same year. This is a function of the truncated nature of the preliminary file; cause-of-death information may not be available or may be incomplete when preliminary data are sent to NCHS, but is available later for final data processing.

Ranking for leading causes of death is based on number of deaths. ${ }^{13}$ Infant mortality refers to the death of an infant younger than 1 year. Infant mortality rates (IMRs) were computed by dividing the total number of infant deaths in each calendar year by the total number of live births in the same year. Neonatal mortality rates (NMRs) are shown for infant deaths that occurred at $<28$ days, and postneonatal mortality rates include infant deaths that occurred at 28 days to $<1$ year of age. The denominator for both rates is the number of live births.

The latest infant mortality statistics according to race and Hispanic origin are from 2007 period linked birth/ infant death data. ${ }^{14}$ In this data set, the death certificate was linked with the corresponding birth certificate for each infant who died in the United States in 2007. The purpose of this linkage was to use additional variables available from the birth certificate, such as birth weight, to better interpret infant mortality patterns.

Birth data for 2009 are for selected items that were collected by using both the 1989 (unrevised) and the 2003 (revised) US Standard Certificates of Live
Birth. The 2003 revision is described in detail elsewhere.1,15,16 Twenty-eight states (California, Colorado, Delaware, Florida, Georgia, Idaho, Indiana, lowa, Kansas, Kentucky, Michigan, Montana, Nebraska, New Hampshire, New Mexico, New York [including New York City], North Dakota, Ohio, Oregon, Pennsylvania, South Carolina, South Dakota, Tennessee, Texas, Utah, Vermont, Washington, and Wyoming) had implemented the revised birth certificates as of January 1, 2009 (accounting for 66\% of 2009 births). ${ }^{1}$

Mortality data for 2009 were collected by using both the 1989 (unrevised) and 2003 (current, or "revised") versions of the US Standard Certificate of Death. The 2003 revision is described in detail elsewhere. ${ }^{3,4,16} \mathrm{~A}$ list of the 30 reporting areas with revised death certificates as of January 1, 2009, is available elsewhere. ${ }^{3}$ The remaining 21 areas reported data in 2009 on the basis of the 1989 "unrevised" death certificate. All mortality data items presented in this report are considered comparable between revisions; and revised and unrevised data are combined.

Population denominators for the calculation of birth, death, and fertility rates are estimates based on the population enumerated by the US Census Bureau as of April 1, 2000. Estimates for 2000-2009 and revised estimates for the intercensal period 1991-1999 were produced under a collaborative arrangement between the US Census Bureau and the NCHS. Birth and death rates for these periods were calculated by using reported population data for multiple-race persons bridged back to single-race categories. ${ }^{9,10}$ In addition, the 2000 census counts were modified to be consistent with the 1977 Office of Management and Budget (OMB) race categories. ${ }^{17}$

Data for the international comparisons of births and IMRs were obtained from the 2008 United Nations Demographic 
TABLE 1 Vital Statistics of the United States, Selected Years: 1915-2008 (Final) and 2009 Birth (Final) and Death (Preliminary)

\begin{tabular}{|c|c|c|c|c|c|c|c|c|c|c|}
\hline & \multicolumn{3}{|c|}{ Number } & \multicolumn{7}{|c|}{ Rate $^{a}$} \\
\hline & 2009 & 2008 & 2000 & 2009 & 2008 & 2000 & 1990 & 1980 & 1950 & $1915^{b}$ \\
\hline Live births & 4130665 & 4247694 & 4058814 & 13.5 & 14.0 & 14.4 & 16.7 & 15.9 & 24.1 & 29.5 \\
\hline Fertility rate & NA & NA & NA & 66.7 & 68.6 & 65.9 & 70.9 & 68.4 & 106.2 & 125.0 \\
\hline Deaths & 2436682 & 2471984 & 2403351 & 7.9 & 8.1 & 8.5 & 8.6 & 8.8 & 9.6 & 13.2 \\
\hline Age-adjusted rate & NA & NA & NA & 7.4 & 7.6 & 8.7 & 9.4 & 10.4 & 14.5 & 21.7 \\
\hline Natural increase & 1693983 & 1775710 & 1655463 & 5.5 & 5.8 & 5.9 & 8.1 & 7.1 & 14.5 & 16.3 \\
\hline Infant mortality & 26531 & 28059 & 28035 & 6.42 & 6.61 & 6.89 & 9.2 & 12.6 & 29.2 & 99.9 \\
\hline Population base (in thousands) & NA & NA & NA & 307007 & 304060 & 281422 & 248710 & 226546 & 150697 & 100546 \\
\hline
\end{tabular}

2009 data for births are final. Data for 2008 and all earlier years are final. Populations are as of July 1 for 2008 and 2009, and as of April 1 in 1950, 1980, 1990, and 2000. Population for 1915 is the midyear estimate based on the April 15, 1910, census. NA, not applicable. Data sources: Centers for Disease Control and Prevention/NCHS, National Vital Statistics System, and the US Census Bureau.

a Rates per 1000 population, except for fertility, which is per 1000 women aged 15 to 44 years of age, and infant mortality, which is per 1000 live births.

b Birth rate was adjusted to include states not in registration area (10 states and the District of Columbia when started in 1915). Death rate is for death registration area. The IMR is for birth registration area.

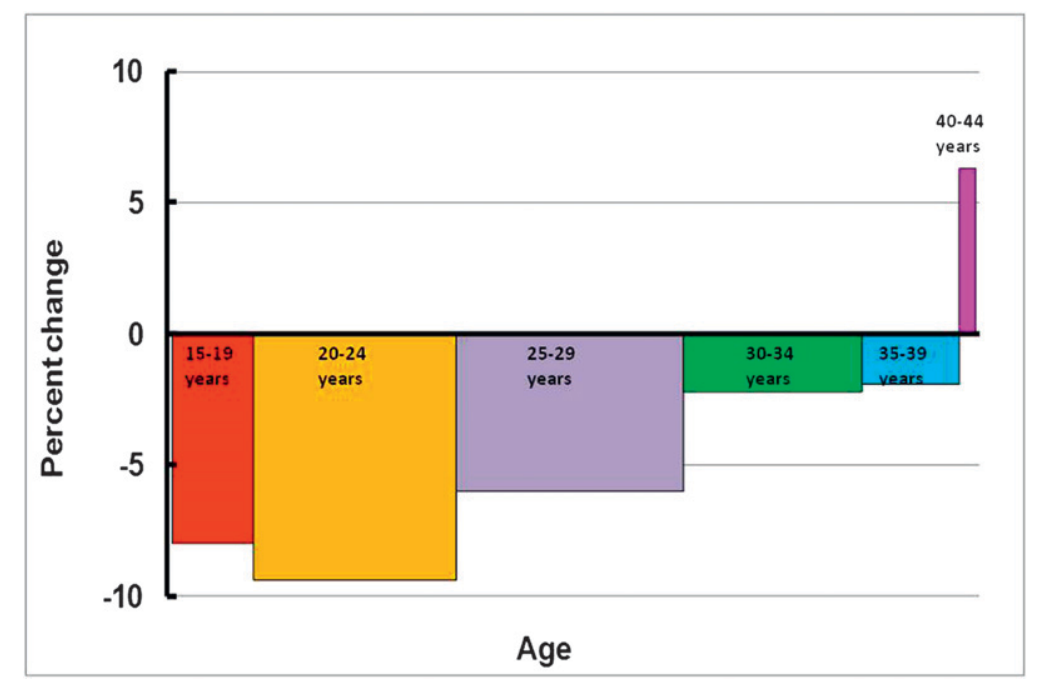

\section{FIGURE 1}

Percent change in birth rates by selected age of mother: United States, 2007-2009. Note: The area of each column represents the group's contribution to the overall change. Column widths are proportional to the number of births in 2007 in each group. See Sutton et al. ${ }^{19}$ Source: CDC/NCHS, National Vital Statistics System.

Yearbook ${ }^{18}$ and other sources, as described below.

NOTE: National data on prenatal care and smoking during pregnancy are not currently available and are not included in this article. An upcoming NCHS report will include detailed 2009 data on these topics for states that have implemented the 2003 revision of the US Standard Certificate of Live Birth.

\section{NATURAL INCREASE}

Nearly 1.7 million persons were added to the US population in 2009 as a result of natural increase, or the excess of births over deaths (Table 1). ${ }^{1-4}$ The rate of natural increase was 5.5 persons per 1000 population in 2009 .

\section{BIRTHS}

In 2009, there were 4130665 births, $\sim 3 \%$ fewer than in 2008 (4 247694 ) (Table 1). ${ }^{1}$ The crude birth rate decreased by $4 \%$ in 2009 to 13.5 births per 1000 total population from 14.0 in 2008. The general fertility rate (the number of births per 1000 women aged 15-44 years) dropped $3 \%$ in 2009 to 66.7. Birth rates decreased among women of all age groups $<40$ years between 2007 and 2009. Rates increased for women 40 and older (Fig 1).1,19 The total fertility rate in 2009 was 2007.0 births per 1000 women, a $4 \%$ decrease compared with the rate in 2008 (2084.5) (Table 2). The total fertility rate estimates the number of births that a hypothetical group of 1000 women would have if they experienced, throughout their childbearing years, the age-specific birth rates observed in a given year.

\section{Racial and Ethnic Composition}

The general fertility rate declined for the 3 largest race and Hispanic-origin groups in 2009, down $2 \%$ for nonHispanic white women, $3 \%$ for nonHispanic black women, and $6 \%$ for Hispanic women. The rates also declined by $3 \%$ for Native American women and $4 \%$ for Asian or Pacific Islander women. Fertility rates for these 5 groups ranged from a low of 58.5 births per 1000 women aged 15 to 44 for nonHispanic white women to a high of 93.3 for Hispanic women in 2009 (Table 2).

\section{Trends in Age-Specific Birth Rates}

\section{Teenaged Childbearing}

The teenage birth rate (15-19 years) in 2009 is the lowest ever reported in the United States in the nearly 7 decades for which a consistent series of data are available. ${ }^{1,20}$ It dropped $6 \%$ from 
TABLE 2 Age-Specific Birth Rates and Total Fertility Rates by Race and Hispanic Origin of Mother United States, 2009

\begin{tabular}{lrrrrrrrrrr}
\hline & \multicolumn{9}{c}{ Age-Specific Birth Rate by Age of Mother } & \multicolumn{2}{c}{ Total Fertility } \\
\cline { 2 - 7 } Rate $^{\mathrm{b}}$
\end{tabular}

Race and Hispanic origin are reported separately on birth certificates. Persons of Hispanic origin may be of any race. Race categories are consistent with the 1977 OMB standards. Thirty-three states and the District of Columbia reported multiplerace data in 2009. Multiple-race data for these states were bridged to the single-race categories of the $19770 \mathrm{MB}$ standards for comparability with other states. Data source: Centers for Disease Control and Prevention/NCHS, National Vital Statistics System, natality.

a Rates per 1000 women in age-specific group

b Sum of age-specific birth rates times 5 (includes rates for ages 10-14, 15-19, and 45-49 years, not shown separately).

${ }^{\mathrm{c}}$ Relates the number of births to women of all ages (women aged 15-44 years).

d Includes births to Aleuts and Eskimos.

e Includes all persons of Hispanic origin of any race.
2008 to 2009. The 2009 rate was 39.1 births per 1000 teenagers aged 15 to 19 years, down from 41.5 in 2008 . The birth rate for teenagers aged 15 to 17 years decreased $7 \%$ to 20.1 per 1000 in 2009, and the birth rate for older teenagers aged 18 to 19 years dropped $6 \%$ to 66.2 per 1000 (Table 3).
TABLE 3 Birth Rates for Teens According to Age, Race, and Hispanic Origin, United States, Selected Years: 1991-2009

\begin{tabular}{|c|c|c|c|c|c|c|c|c|}
\hline \multirow{2}{*}{$\begin{array}{c}\text { Age, Race, and Hispanic } \\
\text { Origin of Mother }\end{array}$} & \multicolumn{5}{|c|}{ Birth Rate ${ }^{a}$} & \multicolumn{3}{|c|}{ Percent Change } \\
\hline & 2009 & 2008 & 2007 & 2005 & 1991 & 2007-2009 & 2005-2007 & $1991-2009$ \\
\hline \multicolumn{9}{|l|}{$15-19 y$} \\
\hline All races & 39.1 & 41.5 & 42.5 & 40.5 & 61.8 & -8 & 5 & -37 \\
\hline Non-Hispanic whiteb & 25.6 & 26.7 & 27.2 & 25.9 & 43.4 & -6 & 5 & -41 \\
\hline Non-Hispanic black ${ }^{b}$ & 59.0 & 62.8 & 64.2 & 60.9 & 118.2 & -8 & 5 & -50 \\
\hline Asian or Pacific Islander & 14.7 & 16.2 & 16.9 & 17.0 & 27.3 & -13 & $\square^{c}$ & -46 \\
\hline Native American ${ }^{d}$ & 55.5 & 58.4 & 59.3 & 52.7 & 84.1 & -6 & 13 & -34 \\
\hline Hispanic ${ }^{\mathrm{b} e \mathrm{e}}$ & 70.1 & 77.5 & 81.8 & 81.7 & 104.6 & -14 & $\longrightarrow^{c}$ & -33 \\
\hline \multicolumn{9}{|l|}{$15-17$ y } \\
\hline All races & 20.1 & 21.7 & 22.1 & 21.4 & 38.6 & -9 & 3 & -48 \\
\hline Non-Hispanic whiteb & 11.0 & 11.5 & 11.8 & 11.5 & 23.6 & -7 & 3 & -53 \\
\hline Non-Hispanic blackb & 32.1 & 34.8 & 35.8 & 34.9 & 86.1 & -10 & 3 & -63 \\
\hline Asian or Pacific Islander & 7.1 & 7.9 & 8.2 & 8.2 & 16.3 & -13 & $\square^{\mathrm{c}}$ & -56 \\
\hline Native Americand & 30.6 & 32.5 & 31.8 & 30.5 & 51.9 & -4 & $-^{c}$ & -41 \\
\hline Hispanic ${ }^{\mathrm{b} \cdot \mathrm{e}}$ & 41.0 & 46.1 & 47.9 & 48.5 & 69.2 & -14 & -1 & -41 \\
\hline \multicolumn{9}{|l|}{$18-19$ y } \\
\hline All races & 66.2 & 70.6 & 73.9 & 69.9 & 94.0 & -10 & 6 & -30 \\
\hline Non-Hispanic whiteb & 46.1 & 48.5 & 50.4 & 48.0 & 70.6 & -9 & 5 & -35 \\
\hline Non-Hispanic blackb & 97.5 & 104.6 & 109.3 & 103.0 & 162.2 & -11 & 6 & -40 \\
\hline Asian or Pacific Islander & 25.8 & 28.4 & 29.9 & 30.1 & 42.2 & -14 & $-^{c}$ & -39 \\
\hline Native American ${ }^{d}$ & 90.5 & 96.6 & 101.6 & 87.6 & 134.2 & -11 & 16 & -33 \\
\hline Hispanic ${ }^{\text {bee }}$ & 114.0 & 127.2 & 137.2 & 134.6 & 155.5 & -17 & 2 & -27 \\
\hline
\end{tabular}

Race and Hispanic origin are reported separately on birth certificates. Persons of Hispanic origin may be of any race. Race categories are consistent with the 1977 OMB standards. Thirty-three states plus the District of Columbia in 2009, 30 states in 2008, 27 states in 2007, and 19 states in 2005 reported multiple-race data. Multiple-race data for these states were bridged to the single-race categories of the 1977 OMB standards for comparability with other states. Data source: Centers for Disease Control and Prevention/NCHS, National Vital Statistics System, natality.

a Rates per 1000 women in specified group.

b In 1991 excludes data for New Hampshire, which did not report Hispanic origin on the birth certificate

${ }^{c}$ Not statistically significant

d Includes births to Aleuts and Eskimos.

e Includes all persons of Hispanic origin of any race.

\section{Childbearing for Women in Their} $20 \mathrm{~s}$ and $30 \mathrm{~s}$

Birth rates declined for women in all 5year age groups from 20 to 39 years. The birth rate reached a record low for women aged 20 to 24 years in 2009 , falling $7 \%$ to 96.3 births per 1000 women, ${ }^{1}$ from 103.0 in 2008. The rate for women aged 25 to 29 years also decreased in 2009 to 110.5 (a drop of $4 \%$ from 2008). The birth rate in 2009 for women aged 30 to 34 declined $2 \%$ to 97.7 . For women 35 to 39 years the rate again declined by $1 \%$ in 2009, to 46.5 per 1000 women.

\section{Childbearing for Women 40 and Over}

The birth rate for women aged 40 to 44 years increased $3 \%$ from 9.8 in 2008 to 10.1 in 2009. It was the only age-specific rate to increase in 2009.1-19 The birth rate for women aged 45 to 49 years remained unchanged from 2008 at 0.7 (data not shown); this rate has trended upward since 1992. ${ }^{1}$

\section{Unmarried Mothers}

The total number of birth to unmarried women fell 2\% in 2009, to 1693658 . The birth rate for unmarried women in 2009 was 50.5 births per 1000 unmarried women aged 15 to 44 years, a decline of $4 \%$ from 2008 . The proportion of all births to unmarried women increased without interruption from 1997 to $2009 .{ }^{1}$ In 2009, $41.0 \%$ of births were to unmarried women, compared with $40.6 \%$ in $2008,33.2 \%$ in 2000 , and $18.4 \%$ in $1980 .{ }^{1}$ The proportion of births to unmarried women increased for the 3 largest race and Hispanicorigin population groups between 2008 and 2009 (Table 4). Births to unmarried women increased from 2008 to 2009 for each age group 25 years and older, whereas they declined for women younger than age 25 . In 2009, $87 \%$ of births to teenagers and $62 \%$ of births to women aged 20 to 24 were nonmarital. One in 5 births to women 30 and older were to unmarried women. ${ }^{1}$ 


\begin{tabular}{|c|c|c|c|c|c|c|c|c|c|c|c|c|}
\hline & \multicolumn{3}{|c|}{ All Races } & \multicolumn{3}{|c|}{$\begin{array}{l}\text { Non-Hispanic } \\
\text { White }\end{array}$} & \multicolumn{3}{|c|}{$\begin{array}{l}\text { Non-Hispanic } \\
\text { Black }\end{array}$} & \multicolumn{3}{|c|}{ Hispanica } \\
\hline & 2009 & 2008 & 1990 & 2009 & 2008 & $1990^{\mathrm{b}}$ & 2009 & 2008 & $1990^{\mathrm{b}}$ & 2009 & 2008 & $1990^{\mathrm{b}}$ \\
\hline \multicolumn{13}{|l|}{ Mother } \\
\hline$<20$ y of age & 10.0 & 10.4 & 12.8 & 7.3 & 7.5 & 9.6 & 16.4 & 17.1 & 23.2 & 13.8 & 14.1 & 16.8 \\
\hline$\geq 40$ y of age & 2.8 & 2.7 & 1.2 & 3.0 & 2.9 & 1.2 & 2.2 & 2.1 & 0.8 & 2.3 & 2.2 & 1.2 \\
\hline Unmarried & 41.0 & 40.6 & 28.0 & 29.0 & 28.7 & 16.9 & 72.8 & 72.3 & 66.7 & 53.2 & 52.6 & 36.7 \\
\hline Diabetes during pregnancy & 4.8 & 4.6 & 2.1 & 4.4 & 4.3 & 2.2 & 4.2 & 4.0 & 1.8 & 5.0 & 4.8 & 2.0 \\
\hline $\begin{array}{l}\text { Pregnancy-associated } \\
\text { hypertension }\end{array}$ & 4.1 & 3.9 & 2.7 & 4.6 & 4.4 & 3.0 & 5.0 & 4.8 & 2.8 & 2.9 & 2.8 & 1.8 \\
\hline Health care utilization & & & & & & & & & & & & \\
\hline Midwife-attended births ${ }^{c}$ & 7.6 & 7.5 & 3.9 & 7.5 & 7.3 & 3.2 & 6.9 & 6.9 & 4.4 & 8.1 & 8.2 & 6.2 \\
\hline Cesarean delivery rate & 32.9 & 32.3 & 22.7 & 32.8 & 32.4 & 23.4 & 35.4 & 34.5 & 22.1 & 31.6 & 31.0 & 21.2 \\
\hline Wt gain of $>40 \mathrm{lbs}^{\mathrm{d}}$ & 20.8 & 20.8 & 15.9 & 23.5 & 23.4 & 16.5 & 20.5 & 20.2 & 14.8 & 16.1 & 16.3 & 14.1 \\
\hline \multicolumn{12}{|l|}{ Infant } & \\
\hline LBWe & 8.16 & 8.18 & 7.0 & 7.19 & 7.22 & 5.6 & 13.61 & 13.71 & 13.3 & 6.94 & 6.96 & 6.1 \\
\hline $\begin{array}{l}\text { VLBWe } \\
\text { Gestational age }\end{array}$ & 1.45 & 1.46 & 1.27 & 1.16 & 1.18 & 0.93 & 3.06 & 3.01 & 2.93 & 1.19 & 1.20 & 1.03 \\
\hline Preterm birth ${ }^{f}$ & 12.18 & 12.33 & 10.6 & 10.92 & 11.14 & 8.5 & 17.47 & 17.54 & 18.9 & 11.97 & 12.10 & 11.0 \\
\hline Earlyf & 3.51 & 3.56 & 3.3 & 2.91 & 2.98 & 2.4 & 6.22 & 6.28 & 7.4 & 3.33 & 3.33 & 3.2 \\
\hline $\begin{array}{l}\text { Late }^{f} \\
\text { Multiple births }\end{array}$ & 8.66 & 8.77 & 7.3 & 8.00 & 8.16 & 6.1 & 11.24 & 11.27 & 11.5 & 8.64 & 8.77 & 7.8 \\
\hline $\begin{array}{l}\text { Live births in twin deliveries } \\
\quad \text { (per } 1000 \text { live births) }\end{array}$ & 33.2 & 32.6 & 22.6 & 37.0 & 36.6 & 22.9 & 38.0 & 36.8 & 26.7 & 22.5 & 22.3 & 18.0 \\
\hline $\begin{array}{l}\text { Live births in higher-order } \\
\text { multiple deliveries } \\
\text { (per } 100000 \text { live births) }\end{array}$ & 153.5 & 147.6 & 72.8 & 201.4 & 198.1 & 89.8 & 105.6 & 91.3 & 46.2 & 83.5 & 80.1 & 39.4 \\
\hline
\end{tabular}

Race and Hispanic origin are reported separately on birth certificates. Persons of Hispanic origin may be of any race. Race categories are consistent with the $19770 \mathrm{MB}$ standards. Three-three states and the District of Columbia in 2009 and 30 states in 2008 reported multiple-race data. Multiple-race data for these states were bridged to the single-race categories of the $19770 \mathrm{MB}$ standards for comparability with other states. Data source: Centers for Disease Control and Prevention/NCHS, National Vital Statistics System, natality.

a Includes all persons of Hispanic origin of any race.

b Excludes data for New Hampshire and Oklahoma, which did not report Hispanic origin.

c Delivered by certified nurse midwives.

d Mother gained more than 40 pounds during pregnancy.

e VLBW is birth weight of $<1500 \mathrm{~g}(3 \mathrm{lb}, 4 \mathrm{oz}$ ), and LBW is birth weight of $<2500 \mathrm{~g}$ ( $5 \mathrm{lb}, 8 \mathrm{oz}$ ).

f Preterm indicates birth before 37 completed weeks of gestation, early preterm indicates birth before 34 completed weeks of gestation, and late preterm indicates birth between 34 and 36 completed weeks of gestation.

\section{Cesarean Delivery}

The total cesarean-delivery rate rose to $32.9 \%$ in 2009 , marking the thirteenth consecutive year of increase and another record high for the nation (Table 4). The rate has climbed by nearly $60 \%$ since 1996 (20.7\%); however, in the past few years, the pace has slowed. ${ }^{1}$ From 2008 to 2009 , cesarean delivery rates increased $1 \%$ to $2 \%$ for all maternal age groups over age 20. Increases were reported for all race and Hispanicorigin groups: non-Hispanic white (1\%), Hispanic, American Indian or Alaska native, and Asian or Pacific Islander (2\%), and non-Hispanic black (3\%). Since 1994, non-Hispanic black women have had the highest cesarean delivery. ${ }^{1}$

\section{Multiple Births}

The twin birth rate rose $2 \%$ in 2009 to 33.2 twins per 1000 total births (Table 4). However, the rise appears to have slowed to $<1 \%$ per year in the period from 2005 to 2009, compared with annual increases of nearly $3 \%$ during the 1990s. The rate of twin births had increased by $76 \%$ since $1980 .{ }^{1}$

The triplet/+ rate (the number of births in triplet and higher-order multiples per 100000 total births) for 2009 was 153.5 per 100000 total births, a rise of $4 \%$ from 2008 (Table 4). This was the first significant rise for this rate since 2001. The triplet/+ rate increased rapidly during the 1980s and 1990s, peaking in 1998 (193.5). The rates have since fluctuated but have generally trended downward. ${ }^{1}$

Babies born in twin and triplet/+ deliveries are much more likely than singletons to be born small, and accordingly, are eight times as likely to die in the first month of life..$^{21}$ Ten percent of twins and $35 \%$ of triplets were born at very low birth weight in 2009 compared with $1 \%$ of singletons. Triplets weigh about half that of singleton infants; the average twin weighs 2 pounds less than the average singleton at birth. ${ }^{1}$

\section{Preterm Birth}

The preterm birth rate was $12.18 \%$ in 2009 , the third consecutive year of decline. ${ }^{1}$ In 2008, the rate was 12.33 . As shown in Fig 2, the preterm rate 


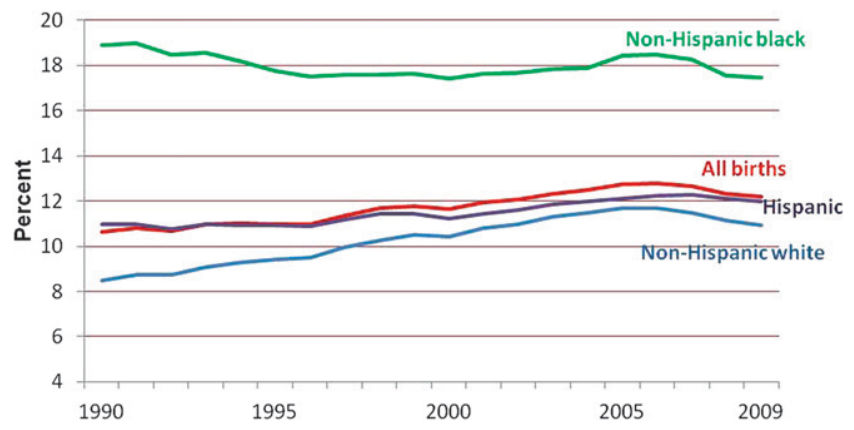

\section{FIGURE 2}

Preterm birth rates by race and Hispanic origin of mother: United States, 1990-2009. Note: Preterm birth is $<37$ completed weeks of gestation. Source: CDC/NCHS, National Vital Statistics System.

(infants delivered at $<37$ completed weeks of gestation per 100 births) rose from 1990 to 2006. ${ }^{1}$ Declines were observed, however, from 2008 to 2009 among late-preterm infants (at 34-36 weeks), from $8.77 \%$ to $8.66 \%$ and early preterm $(<34$ weeks), from $3.56 \%$ to $3.51 \%$ (Table 4). The total preterm rate declined significantly among births to non-Hispanic white (from $11.14 \%$ to $10.92 \%$ ), and Hispanic (from $12.10 \%$ to 11.97\%) infants (Table 4).

\section{Low Birth Weight}

The low birth weight (LBW) (<2500 g) rate was $8.16 \%$ in 2009 , essentially unchanged from the 2008 rate of $8.18 \%$ (Table 4). The percentage of infants born LBW had increased fairly steadily since the mid-1980s $(6.2 \%$ in 1984), but began to decline in $2006 .{ }^{1}$ Rates of very low birth weight $(<1500$ g) were stable, $1.45 \%$ for 2009 . The small observed changes in the LBW rates from 2008 to 2009 among the 3 largest race and Hispanic origin groups were not statistically significant (Table 4).

Over the past several decades, national LBW levels have been influenced by the rise in the rate of multiple births; more than one-half of these infants weigh
$<2500$ g at birth. ${ }^{1} \mathrm{~A}$ rise in LBW was also observed between 1990 and 2006 for singleton deliveries.

The birth weight distribution has changed markedly since 1990 for all births as well as for singletons only. ${ }^{1}$ During 1990-2009, the percentage of infants weighing $<3500 \mathrm{~g}$ increased, whereas births at higher weights have decreased. The reasons for this shift toward lower birth weights are not fully understood, but may include obstetric intervention earlier in pregnancy, older maternal age, and increased use of infertility therapies. ${ }^{23,24}$

\section{INFANT MORTALITY}

In 2009 a total of 26531 infant deaths were reported in the United States according to preliminary data. ${ }^{3}$ The IMR was 6.42 infant deaths per 1000 live births, a figure significantly lower (by 3\%) than the 2008 rate of 6.61 . The NMR for 2009 was 4.19, also significantly lower than the 2008 NMR of 4.29 neonatal deaths per 1000 live births.

Data for 2007 linked birth/infant deaths show wide and persistent variation in

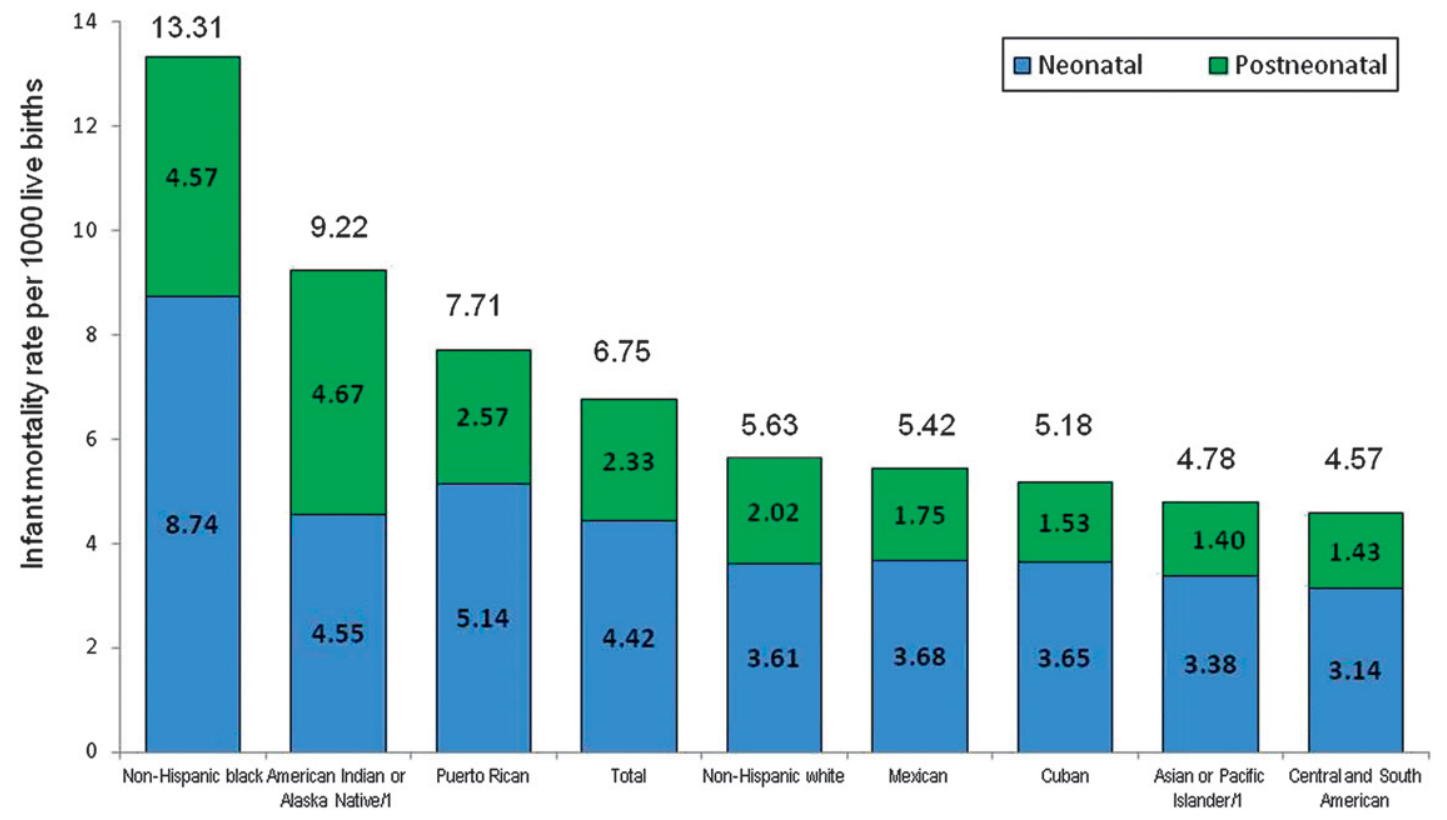

FIGURE 3

Infant, neonatal, and postneonatal mortality rates by race and Hispanic origin of mother, United States, 2007. Includes persons of Hispanic and non-Hispanic origin. Note: Neonatal is $<28$ days and postneonatal is 28 days to $<1$ year. See Mathews et al. ${ }^{14}$. Source: CDC/NCHS, National Vital Statistics System. 
IMRs according to race and Hispanic origin. ${ }^{14}$ As in past years, the highest rate was among infants born to nonHispanic black mothers, ${ }^{25} 13.31$ deaths per 1000 live births, more than double the rate of infants born to non-Hispanic white mothers (5.63) (Fig 3). Among Hispanic subgroups, rates ranged from 4.57 for Central and South Americans mothers, to 7.71 for Puerto Rican mothers. The IMRs for most Hispanic subgroups have fluctuated slightly since 2000.

\section{Geographic Variation in Infant Outcomes}

Table 5 presents 2009 information for states on the percentage of preterm birth, percentage of LBW (final data), IMRs, and NMRs (preliminary data). For 2009, Mississippi had the highest LBW (12.2\%) and preterm (18.0\%) rates. South Dakota had the lowest LBW (5.8\%) rate, and Vermont had the lowest preterm rate $(9.3 \%)$. States in the southeastern United States had the highest infant and neonatal mortality rates. In 2009, IMRs for the states ranged from 4.58 in lowa to 10.02 in Mississippi. The IMR for the District of Columbia was 9.40. These geographic patterns have been observed for many years.

\section{Leading Causes of Infant Death}

In 2009, $55.5 \%$ of all infant deaths (Table 6 ) were attributable to 5 leading causes: congenital malformations, deformations, and chromosomal abnormalities (20.2\%); disorders related to short gestation and LBW, not elsewhere classified (16.8\%); sudden infant death syndrome (8.2\%); newborn affected by maternal complications of pregnancy (6.0\%); and accidents (unintentional injuries) (4.4\%). ${ }^{3}$ These 5 leading causes of infant death are the same as in $2008 .{ }^{4}$

\section{INTERNATIONAL COMPARISONS}

Table 7 shows births for 2009/2010 and IMRs for 2007, 2008, and 2009 for the
TABLE 5 Percent Preterm and Percent LBW (Final), IMR, and NMR (Preliminary), United States and Each State: 2009

\begin{tabular}{|c|c|c|c|c|c|c|c|c|c|}
\hline State of Residence & Preterma & $\mathrm{LBW}^{\mathrm{b}}$ & $\mathrm{IMR}^{\mathrm{c}}$ & $\mathrm{NMR}^{\mathrm{d}}$ & State of Residence & Preterma & LBWb & $\mathrm{IMR}^{\mathrm{c}}$ & $\mathrm{NMR}^{\mathrm{d}}$ \\
\hline United States & 12.2 & 8.2 & 6.42 & 4.19 & & & & & \\
\hline Alabama & 15.6 & 10.3 & 8.42 & 5.15 & Montana & 10.9 & 7.1 & 5.87 & 3.34 \\
\hline Alaska & 10.0 & 5.9 & 6.80 & 2.74 & Nebraska & 11.5 & 7.1 & 5.42 & 3.30 \\
\hline Arizona & 12.7 & 7.1 & 5.98 & 3.98 & Nevada & 13.8 & 8.1 & 5.87 & 3.99 \\
\hline Arkansas & 13.1 & 8.9 & 7.70 & 4.27 & New Hampshire & 9.9 & 6.9 & 4.86 & 3.36 \\
\hline California & 10.3 & 6.8 & 4.94 & 3.33 & New Jersey & 12.0 & 8.3 & 5.12 & 3.63 \\
\hline Colorado & 11.3 & 8.8 & 6.25 & 4.20 & New Mexico & 12.3 & 8.3 & 5.31 & 3.24 \\
\hline Connecticut & 10.2 & 8.0 & 5.50 & 4.19 & New York & 12.2 & 8.2 & 5.32 & 3.65 \\
\hline Delaware & 12.5 & 8.6 & 7.87 & 5.71 & North Carolina & 13.0 & 9.0 & 7.92 & 5.31 \\
\hline District of Columbia & 14.2 & 10.3 & 9.40 & 6.08 & North Dakota & 10.6 & 6.4 & 6.11 & 3.33 \\
\hline Florida & 13.5 & 8.7 & 6.88 & 4.48 & Ohio & 12.3 & 8.6 & 7.68 & 5.21 \\
\hline Georgia & 13.8 & 9.4 & 8.15 & 5.62 & Oklahoma & 13.8 & 8.4 & 7.90 & 4.43 \\
\hline Hawaii & 12.6 & 8.4 & 6.14 & 4.55 & Oregon & 9.8 & 6.3 & 4.81 & 3.33 \\
\hline Idaho & 10.1 & 6.5 & 5.44 & 3.41 & Pennsylvania & 11.5 & 8.3 & 7.14 & 4.88 \\
\hline Illinois & 12.4 & 8.4 & 6.90 & 4.39 & Rhode Island & 11.4 & 8.0 & 6.20 & 4.98 \\
\hline Indiana & 11.9 & 8.3 & 7.82 & 4.96 & South Carolina & 14.5 & 10.0 & 7.41 & 4.49 \\
\hline lowa & 11.3 & 6.7 & 4.58 & 2.72 & South Dakota & 10.9 & 5.8 & 6.70 & 3.77 \\
\hline Kansas & 11.2 & 7.3 & 6.98 & 4.25 & Tennessee & 13.0 & 9.2 & 8.00 & 4.77 \\
\hline Kentucky & 13.6 & 8.9 & 6.79 & 3.49 & Texas & 13.1 & 8.5 & 5.99 & 3.78 \\
\hline Louisiana & 14.7 & 10.6 & 8.69 & 5.09 & Utah & 11.3 & 7.0 & 5.29 & 3.90 \\
\hline Maine & 9.9 & 6.3 & 5.42 & 3.93 & Vermont & 9.3 & 6.7 & 6.22 & 4.42 \\
\hline Maryland & 12.7 & 9.1 & 7.27 & 5.18 & Virginia & 11.4 & 8.4 & 7.14 & 4.67 \\
\hline Massachusetts & 10.9 & 7.8 & 5.03 & 3.85 & Washington & 10.3 & 6.3 & 4.91 & 2.84 \\
\hline Michigan & 12.4 & 8.4 & 7.52 & 5.13 & West Virginia & 12.9 & 9.2 & 7.76 & 5.22 \\
\hline Minnesota & 10.1 & 6.5 & 4.61 & 2.69 & Wisconsin & 10.9 & 7.1 & 6.08 & 3.98 \\
\hline Mississippi & 18.0 & 12.2 & 10.02 & 6.13 & Wyoming & 11.2 & 8.4 & 5.96 & 3.55 \\
\hline Missouri & 12.2 & 8.1 & 7.16 & 4.51 & & & & & \\
\hline
\end{tabular}

Data source: Centers for Disease Control and Prevention/NCHS, National Vital Statistics System.

a Preterm birth is $<37$ weeks of completed gestation.

b $L B W$ is $<2500 \mathrm{~g}$.

c Infant deaths $(<1$ year) per 1000 live births

d Neonatal deaths ( $<28$ days) per 1000 live births.

TABLE 6 Deaths, Percentages of Total Deaths, and Mortality Rates for the 10 Leading Causes of Infant Death: United States, 2008 (Final) and 2009 (Preliminary)

\begin{tabular}{|c|c|c|c|c|c|c|c|}
\hline \multirow{2}{*}{$\begin{array}{l}\text { Causes of Death and International } \\
\text { Classification of Diseases, } \\
\text { 10th Revision Codes }\end{array}$} & \multirow[t]{2}{*}{ Rank $^{a}$} & \multicolumn{3}{|c|}{2009} & \multicolumn{3}{|c|}{2008} \\
\hline & & $n$ & $\%$ & Rate $^{\mathrm{c}}$ & $n$ & $\%$ & Rate $^{\mathrm{c}}$ \\
\hline All causes & $-_{b}^{b}$ & 26531 & 100.0 & 642.1 & 28059 & 100.0 & 660.6 \\
\hline $\begin{array}{l}\text { Congenital malformations, deformations } \\
\text { and chromosomal abnormalities (Q00-099) }\end{array}$ & 1 & 5358 & 20.2 & 129.7 & 5638 & 20.1 & 132.7 \\
\hline $\begin{array}{l}\text { Disorders related to short gestation and low } \\
\text { birth weight, not elsewhere classified (P07) }\end{array}$ & 2 & 4463 & 16.8 & 108.0 & 4754 & 16.9 & 111.9 \\
\hline Sudden infant death syndrome (R95) & 3 & 2168 & 8.2 & 52.5 & 2353 & 8.4 & 55.4 \\
\hline $\begin{array}{l}\text { Newborn affected by maternal complications } \\
\text { of pregnancy (P01) }\end{array}$ & 4 & 1586 & 6.0 & 38.4 & 1765 & 6.3 & 41.6 \\
\hline Accidents (unintentional injuries) (V01-X59) & 5 & 1158 & 4.4 & 28.0 & 1315 & 4.7 & 31.0 \\
\hline $\begin{array}{l}\text { Newborn affected by complications of } \\
\text { placenta, cord, and membranes (P02) }\end{array}$ & 6 & 1022 & 3.9 & 24.7 & 1080 & 3.8 & 25.4 \\
\hline Bacterial sepsis of newborn (P36) & 7 & 682 & 2.6 & 16.5 & 700 & 2.5 & 16.5 \\
\hline Respiratory distress of newborn (P22) & 8 & 587 & 2.2 & 14.2 & 630 & 2.2 & 14.8 \\
\hline $\begin{array}{l}\text { Diseases of the circulatory } \\
\text { system (100-199) }\end{array}$ & 9 & 565 & 2.1 & 13.7 & 594 & 2.1 & 14.0 \\
\hline Neonatal hemorrhage (P50-P52,P54) & 10 & 537 & 2.0 & 13.0 & 556 & 2.0 & 13.1 \\
\hline
\end{tabular}

Data source: Centers for Disease Control and Prevention/NCHS, National Vital Statistics System: mortality, 2009 and 2008 (www.cdc.gov/nchs/nvss/mortality_tables.htm).

a Rank is based on 2009 data.

b Indicates that data are not applicable.

c IMRs are per 100000 live births. 
TABLE 7 Number of Live Births for 2009 and IMRs for 2007, 2008, and 2009 for 30 Countries

\begin{tabular}{|c|c|c|c|c|}
\hline \multirow[t]{2}{*}{ Country } & \multirow[t]{2}{*}{ No. of Births in $2009 / 2010^{a}$} & \multicolumn{3}{|c|}{ IMR } \\
\hline & & 2009 & 2008 & 2007 \\
\hline Hong Kong & 82095 & 1.7 & 1.8 & 1.8 \\
\hline Japan & 1070035 & 2.4 & 2.6 & 2.6 \\
\hline Sweden & $115641^{\mathrm{a}}$ & 2.5 & 2.5 & 2.5 \\
\hline Finland & $60980^{a}$ & 2.6 & 2.6 & 2.7 \\
\hline Czech Republic & $117153^{a}$ & 2.9 & 2.8 & 3.1 \\
\hline Norway & $61442^{a}$ & 3.1 & 2.7 & 3.1 \\
\hline Greece & 117933 & 3.1 & 2.7 & 3.5 \\
\hline Denmark & 63411 & 3.1 & 4.0 & 4.0 \\
\hline Republic of Korea & 444849 & 3.2 & 3.5 & 3.6 \\
\hline Ireland & $73940^{a}$ & 3.2 & 3.8 & 3.1 \\
\hline Spain & 479 999a & 3.3 & 3.3 & 3.5 \\
\hline Belgium & $127000^{a}$ & 3.4 & 3.7 & 4.0 \\
\hline Germany & $681000^{a}$ & 3.5 & 3.5 & 3.9 \\
\hline Portugal & 101320 & 3.6 & 3.3 & 3.4 \\
\hline Italy & $561980^{a}$ & 3.7 & 3.3 & 3.5 \\
\hline Austria & $78742^{\mathrm{a}}$ & 3.8 & 3.7 & 3.7 \\
\hline Israel & $165950^{a}$ & 3.8 & 3.8 & 3.9 \\
\hline Netherlands & $183866^{a}$ & 3.8 & 3.8 & 4.1 \\
\hline France & $829000^{a}$ & 3.9 & 3.8 & 3.8 \\
\hline Switzerland & $80000^{a}$ & 4.3 & 4.0 & 3.9 \\
\hline Australia & 295738 & 4.3 & 4.1 & 4.2 \\
\hline United Kingdom & $778823^{a}$ & 4.7 & 4.6 & 4.8 \\
\hline Cuba & 130036 & 4.8 & 4.7 & 5.3 \\
\hline New Zealand & 62543 & 4.9 & 5.0 & 4.9 \\
\hline Canada & 377886 & $\simeq^{b}$ & $5.1^{\mathrm{c}}$ & 5.1 \\
\hline Hungary & $90350^{a}$ & 5.1 & 5.6 & 5.9 \\
\hline Croatia & 44577 & 5.3 & 4.5 & 5.6 \\
\hline Poland & $413300^{a}$ & 5.6 & 5.6 & 6 \\
\hline Slovenia & $60410^{a}$ & 5.7 & 5.9 & 6.1 \\
\hline United States & 4130665 & $6.4^{\mathrm{d}}$ & 6.6 & 6.8 \\
\hline
\end{tabular}

Data sources: Tables 9 and 15 in United Nations Demographic Yearbook, 2008.18

a Data are for 2010.

b Data are not available.

c Statistics Canada, CANSIM, table 102-0504 and Catalogue no. 84F0211X.

a Preliminary data.

United States and 29 other countries with at least 40000 births. Data for these countries were obtained from the United Nations Demographic Yearbook, ${ }^{18}$ the United Nations demographic Web site, ${ }^{26}$ and Organisation for Economic Co-operation and Development publications. ${ }^{27}$ Countries are ordered from the lowest to highest IMR in 2009. Hong Kong reported an IMR $<2$ infant deaths per 1000 live births for all 3 years. Nine countries had an IMR half the US rate in 2009, and the rate was $<5.0$ infant deaths per 1000 live births for 24 countries. The potential reasons for the higher IMR in the United States are discussed elsewhere. ${ }^{4,28-31}$

\section{DEATHS}

There were 2436682 deaths in the United States in 2009 (Table 1), 35302 less than in 2008. Age-adjusted death rates are better indicators of the risk of mortality over time than crude death rates, because they control for changes in the age composition of the population. The age-adjusted death rate decreased by $2.6 \%$ from 7.6 deaths per 1000 US standard population in 2008 , to 7.4 in 2009. This was a record Iow for the United States. ${ }^{3}$

The 2008 life tables show a difference in life expectancy at birth for gender, race, and Hispanic origin. Hispanic females have the highest life expectancy at birth (83.3 years), followed by non-Hispanic white females (80.8 years), Hispanic males (78.4 years), non-Hispanic black females (76.9), non-Hispanic white males (75.9), and non-Hispanic black males (70.2) ${ }^{4,32}$ The estimated life expectancy at birth for a given year represents the average number of years that a group of infants would be expected to live if, throughout their lifetime, they were to experience the age-specific death rates that prevailed during the year of their birth.

\section{Deaths Among Children}

A total of 21542 children and adolescents aged 1 to 19 years died in the United States in 2009 (Table 8). ${ }^{3}$ The death rate for children aged 1 to 19 years decreased $6.5 \%$ from 29.1 per 100 000 population in 2008 to 27.2 in 2009.

For all children aged 1 to 19 years, the leading cause of death was accidents (unintentional injuries), which accounted for $36.5 \%$ of all deaths in 2009 and $38.9 \%$ of all deaths in 2008. The second leading cause of death was homicide, accounting for $12.1 \%$ of all deaths in 2009 and $12.4 \%$ of all deaths in 2008. Between 2008 and 2009, the death rate decreased for unintentional injuries, homicide, septicemia, and cerebrovascular diseases. The preliminary death rate increased for influenza and pneumonia because of the increase in deaths from influenza A (H1N1) in 2009. ${ }^{3}$ Rates did not change significantly for the other leading causes of death among children.

\section{The Release of Important New Health Data From the Revised Birth Certificate}

The 2003 US Standard Certificate of Live Birth includes an array of new health items that can be used to describe patterns and trends in maternal and newborn risk, and the utilization and impact of health care. ${ }^{15,16}$ These important new items will be released by Centers of Disease Control and Prevention's National Center for Health 
TABLE 8 Deaths and Death Rates for the 5 Leading Causes of Childhood Death in Specified Age Groups, United States, 2008 (Final) and 2009 (Preliminary)

\begin{tabular}{|c|c|c|c|c|c|c|c|}
\hline \multirow{2}{*}{$\begin{array}{l}\text { Age, Causes of Death, and International Classification } \\
\text { of Diseases, Tenth Revision Codes }{ }^{12}\end{array}$} & \multirow[t]{2}{*}{ Rank $^{\mathrm{a}}$} & \multicolumn{3}{|c|}{2009} & \multicolumn{3}{|c|}{2008} \\
\hline & & $n$ & $\%$ & Rate $^{b}$ & $n$ & $\%$ & Rate $^{b}$ \\
\hline \multicolumn{8}{|l|}{ Total: $1-19$ y } \\
\hline All causes & $-^{c}$ & 21542 & 100.0 & 27.2 & 22788 & 100.0 & 29.1 \\
\hline Accidents (unintentional injuries) (V01-X59,Y85- & 1 & 7871 & 36.5 & 9.9 & 8869 & 38.9 & 11.3 \\
\hline Assault (homicide) (*U01-*U02,X85-Y09,Y87.1) & 2 & 2597 & 12.1 & 3.3 & 2836 & 12.4 & 3.6 \\
\hline Intentional self-harm (suicide) ( $\left.{ }^{\star} U 03, X 60-X 84, Y 87.0\right)$ & 3 & 1922 & 8.9 & 2.4 & 1826 & 8.0 & 2.3 \\
\hline Malignant neoplasms (CO0-C97) & 4 & 1896 & 8.8 & 2.4 & 1969 & 8.6 & 2.5 \\
\hline $\begin{array}{l}\text { Congenital malformations, deformations, and } \\
\text { chromosomal abnormalities (Q00-Q99) }\end{array}$ & 5 & 1062 & 4.9 & 1.3 & 1082 & 4.7 & 1.4 \\
\hline Diseases of heart $(|00-109| 11,,|13| 20-,\mid 51)$ & 6 & 679 & 3.2 & 0.9 & 778 & 3.4 & 1.0 \\
\hline Influer & 7 & 521 & 2.4 & 0.7 & 95 & 1.3 & 0.4 \\
\hline Chronic lower respirato & 8 & 260 & 1.2 & 0.3 & 244 & 1.1 & 0.3 \\
\hline Septicem & 9 & 185 & 0.9 & 0.2 & 208 & 0.9 & 0.3 \\
\hline Cereb & 10 & 174 & 0.8 & 0.2 & 232 & 1.0 & 0.3 \\
\hline \multicolumn{8}{|l|}{$1-4 \mathrm{y}$} \\
\hline All causes & $\subset^{c}$ & 4448 & 100.0 & 26.1 & 4730 & 100.0 & 28.3 \\
\hline Accidents (u & 1 & 1446 & 32.5 & 8.5 & 1469 & 31.1 & 8.8 \\
\hline $\begin{array}{l}\text { Congenital } \\
\text { chromos }\end{array}$ & 2 & 485 & 10.9 & 2.8 & 21 & 11.0 & 3.1 \\
\hline Assault & 3 & 385 & 8.7 & 2.3 & 21 & 8.9 & 2.5 \\
\hline Mall & 4 & 349 & 7.8 & 2.0 & 394 & 8.3 & 2.4 \\
\hline Disea & 5 & 154 & 3.5 & 0.9 & 186 & 3.9 & 1.1 \\
\hline \multicolumn{8}{|l|}{$5-9$ y } \\
\hline All cau & $-^{c}$ & 2508 & 100.0 & 12.2 & 2502 & 100.0 & 12.5 \\
\hline Accidents ( & 1 & 776 & 30.9 & 3.8 & 835 & 33.4 & 4.2 \\
\hline Maliǵ & 2 & 467 & 18.6 & 2.3 & .57 & 18.3 & 2.3 \\
\hline $\begin{array}{l}\text { Congenital malformations, deformations, and } \\
\text { chromosomal abnormalities (Q00-Q99) }\end{array}$ & 3 & 189 & 7.5 & 0.9 & 170 & 6.8 & 0.8 \\
\hline de) $\left({ }^{\star} \cup 01-{ }^{\star} \cup 02, X 85-Y 09, Y 87.1\right)$ & 4 & 118 & 4.7 & 0.6 & 113 & 4.5 & 0.6 \\
\hline Influen & 5 & 111 & 4.4 & 0.5 & 40 & 1.6 & 0.2 \\
\hline \multicolumn{8}{|l|}{$10-14$ y } \\
\hline All caus & $\varlimsup^{c}$ & 3121 & 100.0 & 15.6 & 3149 & 100.0 & 15.7 \\
\hline Accide & 1 & 891 & 28.5 & 4.5 & 1024 & 32.5 & 5.1 \\
\hline Malign & 2 & 426 & 13.6 & 2.1 & 433 & 13.8 & 2.2 \\
\hline Intentic & 3 & 259 & 8.3 & 1.3 & 215 & 6.8 & 1.1 \\
\hline Assault (homicide) (*U01-*U02,X85-Y09,Y87.1) & 4 & 201 & 6.4 & 1.0 & 207 & 6.6 & 1.0 \\
\hline $\begin{array}{l}\text { Congenital malformations, deformations, and } \\
\text { chromosomal abnormalities (Q00-099) }\end{array}$ & 5 & 161 & 5.2 & 0.8 & 161 & 5.1 & 0.8 \\
\hline \multicolumn{8}{|l|}{$15-19$ y } \\
\hline All causes & 一 $^{c}$ & 11465 & 100.0 & 53.2 & 12407 & 100.0 & 57.7 \\
\hline Accidents ( & 1 & 4758 & 41.5 & 22.1 & 5541 & 44.7 & 25.8 \\
\hline Assault (homicide) (*U01-*U02,X85-Y09,Y87.1) & 2 & 1893 & 16.5 & 8.8 & 2095 & 16.9 & 9.7 \\
\hline Intentional self-harm (suicide) ( ${ }^{*} \mathrm{U} 03, \mathrm{X} 60-\mathrm{X} 84, \mathrm{Y} 87.0$ ) & 3 & 1656 & 14.4 & 7.7 & 1604 & 12.9 & 7.5 \\
\hline Malig & 4 & 654 & 5.7 & 3.0 & 685 & 5.5 & 3.2 \\
\hline Diseases of heart $(100-|09| 11,,|13| 120-,\mid 51)$ & 5 & 325 & 2.8 & 1.5 & 363 & 2.9 & 1.7 \\
\hline
\end{tabular}

Data source: Centers for Disease Control and Prevention / NCHS, National Vital Statistics System: mortality, 2009 and 2008 (www.cdc.gov/nchs/nvss/mortality tables.htm).

a Rank is based on 2009 data.

b Rate per 100000 population in specified group.

${ }^{\mathrm{c}}$ Indicates that data are not available.

Statistics for the first time in the near future. Newly released topics will include interval between pregnancies, smoking cessation before pregnancy, maternal BMl, the use of infertility treatment, the receipt of Supplemental Nutrition Program for Women, Infants, and Children food, the presence of infections during pregnancy such as Chlamydia and hepatitis B, whether the infant was breastfed before discharge from the hospital, and the source of payment for the delivery. Information on maternal morbidities, including whether the mother experienced a ruptured uterus or was admitted to an ICU, also will be available for the first time from the birth certificate.

These data will first be available for the 28-state 2009 revised reporting area. ${ }^{1}$ This area includes 2.7 million births representing $66 \%$ of all US births in 2009 (see Fig 4). Although data for the 2009 revised reporting area are not generalizable to the nation, when used appropriately, this information should importantly expand our understanding of perinatal health in the United States. Information will be available in several ways: the report "Births: Expanded data for 2009" will present brief descriptive discussions and detailed data tables by maternal age and race/ethnicity on the topics noted above plus many others. A companion report will describe the results of reviews of data quality of the new medical and health items on the birth certificate. More detailed data will be available via the interactive data access tool, VitalStats, ${ }^{33}$ and also via the 2009 natality public-use microdata file. ${ }^{5} \mathrm{~A}$ number of special reports on specific topics such as the risk of gestational diabetes according to maternal $\mathrm{BMI}$, ruptured uterus following labor and delivery, birth intervals, and differences in source of payment for delivery by maternal characteristics will be developed over the next several years.

National transition to the 2003 standard birth certificate has been delayed, but progress has been made. By the end of 2012 , nearly $90 \%$ of all US births will be reported based on the revised birth certificate; the remaining jurisdictions are expected to implement the revised certificate by the end of 2013. Finally, new agreements ${ }^{34}$ (Charles J. Rothwell, MS, personal communication, 2011) between NCHS and its state and jurisdictional vital statistics partners should promote improvements in the quality and the timeliness of these 


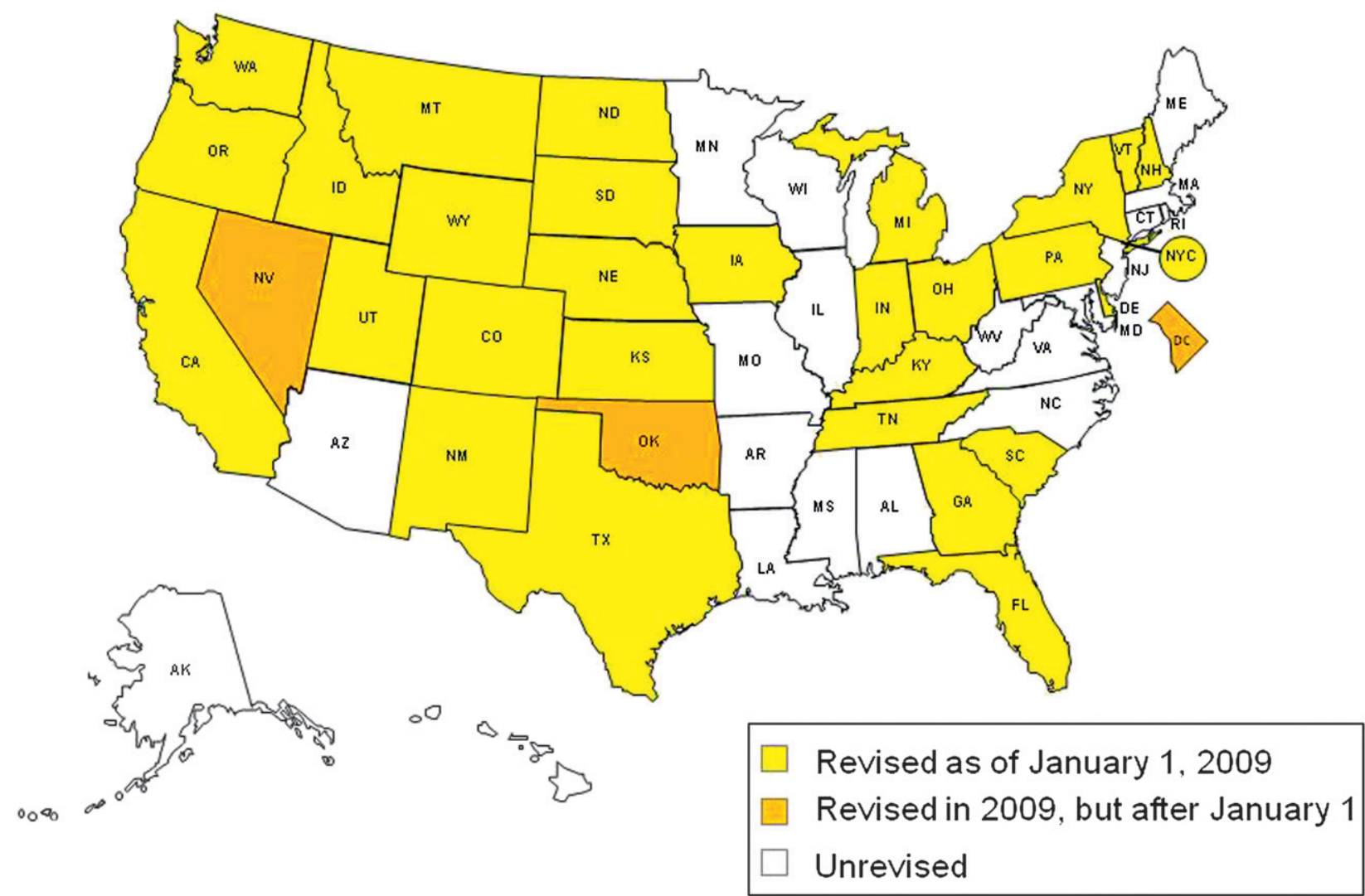

FIGURE 4

Revised Birth Certificate ${ }^{\star}$ Reporting Area, 2009. *2003 US Standard Certificate of Live Birth. Note: See Martin et al. ${ }^{1}$ Source: CDC/NCHS, National Vital Statistics System.

data, making them increasingly useful to public health research.

\section{CONCLUSIONS}

Vital statistics remain a valuable tool for monitoring the health of the US population. Their value is improved through work on the timeliness, quality, and sustainability of this decentralized system. Data collection from the 2003 revised certificates is enhanced by adopting technologically sophisticated yet cost-effective electronic systems. ${ }^{35}$

\section{REFERENCES}

1. Martin JA, Hamilton BE, Ventura SJ, et al. Births: final data for 2009. Natl Vital Stat Rep. 2011;60(1):1-104

2. Martin JA, Hamilton BE, Sutton PD, et al. Births: final data for 2008. Natl Vital Stat Rep. 2010;59(1):1-72

3. Kochanek KD, Xu J, Murphy SL, et al. Deaths: preliminary data for 2009. Natl Vital Stat Rep. 2011;59(4):1-51

4. Miniňo AM, Murphy SL, Xu J, et al. Deaths: final data for 2008. Natl Vital Stat Rep. 2011; 59(10):1-157

5. National Center for Health Statistics. Natality public use file and CD-ROM.

Hyattsville, MD: National Center for Health Statistics. Published annually. Available at: www.cdc.gov/nchs/data_access/ VitalStatsOnline.htm. Accessed September 19, 2011

6. National Center for Health Statistics. Mortality public use file and CD-ROM. Hyattsville, MD: National Center for Health Statistics. Published annually. Available at: www.cdc. gov/nchs/data_access/VitalStatsOnline.htm. Accessed September 19, 2011

7. National Center for Health Statistics. Data release policy. Hyattsville, MD: National Center for Health Statistics; 2000. Available at: www.

\section{ACKNOWLEDGMENTS}

We thank Brady E. Hamilton, T.J. Mathews, Marian F. MacDorman, Stephanie J. Ventura, Jiaquan $\mathrm{Xu}$, and Arialdi $\mathrm{M}$. Minino for contributions to the manuscript and Yashodhara Patel for content review.

cdc.gov/nchs/nvss/dvs_data_release.htm. Accessed September 19, 2011

8. Office of Management and Budget. Revisions to the standards for the classification of federal data on race and ethnicity. Federal Register 62FR58781-58790, 0ctober 30, 1997. Available at: www.census. gov/population/www/socdemo/race/ ombdir15.html. Accessed September 19, 2011

9. Ingram DD, Parker JD, Schenker N, et al. United States Census 2000 population with bridged race categories. Vital Health Stat 2. $2003 ;(135): 1-55$ 
10. Schenker N, Parker JD. From single-race reporting to multiple-race reporting: using imputation methods to bridge the transition. Stat Med. 2003;22(9):15711587

11. National Center for Health Statistics. User guide to the 2009 natality public use file. Hyattsville, MD: National Center for Health Statistics. Available at: www.cdc.gov/ nchs/about/major/dvs/Vitalstatsonline.htm. Accessed September 19, 2011

12. World Health Organization. International Statistical Classification of Diseases and Related Health Problems, Tenth Revision. 2nd ed. Geneva, Switzerland: World Health Organization; 2004

13. Heron M. Deaths: leading causes for 2007 . Natl Vital Stat Rep. 2011;59(8):1-95

14. Mathews TJ, MacDorman MF. Infant mortality statistics from the 2007 period linked birth/infant death data set. Natl Vital Stat Rep. 2011;59(6):1-30

15. National Center for Health Statistics. U.S. Standard Certificate of Live Birth, 2003 revision. Available at: www.cdc.gov/nchs/ data/dvs/birth11-03final-ACC.pdf. Accessed September 19, 2011

16. National Center for Health Statistics. Report of the panel to evaluate the U.S. standard certificates and reports: appendix B. Available at: www.cdc.gov/nchs/data/ dvs/panelreport_acc.pdf. Accessed September 19, 2011

17. Office of Management and Budget. Race and ethnic standards for federal statistics and administrative reporting. 1977. Statistical Policy Directive 15. Available at: http:// wonder.cdc.gov/wonder/help/populations/ bridged-race/directive15.html. Accessed September 19, 2011

18. United Nations. Tables 9 and 15. In: United Nations Demographic Yearbook, 2008 New York, NY: United Nations; 2010. Available at: http://unstats.un.org/unsd/demographic/ products/dyb/dyb2008.htm. Accessed 0ctober 11, 2011

19. Sutton PD, Mathews TJ, Hamilton BE. Recent decline in births in the United States, 2007 2009. NCHS Data Brief, no. 60. Hyattsville, MD: National Center for Health Statistics; 2011. Available at: www.cdc.gov/nchs/data/ databriefs/db60.htm. Accessed October 19, 2011

20. Ventura SJ, Hamilton BE, U.S. Teenage birth rate resumes decline. NCHS Data Brief, no. 58. Hyattsville, MD: National Center for Health Statistics; 2011. Available at: www. cdc.gov/nchs/data/databriefs/db58.htm/ Accessed October 19, 2011

21. National Center for Health Statistics. Publicuse data file documentation: 2007 period linked birth/infant death data set. Hyattsville, MD: National Center for Health Statistics; Available at: www.cdc.gov/nchs/data_access/ Vitalstatsonline.htm. Accessed January 6, 2012

22. Martin JA, Hamilton BE, Sutton PD, et al. Births: final data for 2007. Natl Vital Stat Rep. 2010;58(24):1-85

23. Engle WA, Kominiarek MA. Late preterm infants, early term infants, and timing of elective deliveries. Clin Perinatol. 2008;35 (2):325-341, vi

24. MacDorman MF, Declercq E, Zhang J. Obstetrical intervention and the singleton preterm birth rate in the United States from 1991-2006. Am J Public Health. 2010; 100(11):2241-2247

25. Mac Dorman MF, Mathews TJ. Understanding racial and ethnic disparities in U.S. infant mortality rates. NCHS Data Brief, no. 74. Hyattsville, MD: National Center for Health Statistics; 2011. Available at: www. cdc.gov/nchs/data/databriefs/db74.htm. Accessed October 19, 2011

26. Table 3. Live births, deaths, and infant deaths, latest available year (1996-2010). http://unstats.un.org/unsd/demographic/
products/vitstats/serATab3.pdf. Accessed October 19, 2011

27. OECDiLibrary. Health: Key Tables from OECD. ISSN 2075-8480. 2011. Available at: www. oecd-ilibrary.org/. Accessed October 19, 2011

28. MacDorman MF, Martin JA, Mathews TJ, Hoyert DL, Ventura SJ. Explaining the 20012002 infant mortality increase in the United States: data from the linked birth/infant death data set. Int J Health Serv. 2005;35 (3): 415-442

29. Sepkowitz S. International rankings of infant mortality and the United States' vital statistics natality data collecting systemfailure and success. Int J Epidemiol. 1995; 24(3):583-588

30. Kramer MS, Platt RW, Yang H, Haglund B, Cnattingius S, Bergsjo P. Registration artifacts in international comparisons of infant mortality. Paediatr Perinat Epidemiol. 2002. 16(1):16-22

31. MacDorman MF, Mathews TJ. Behind international rankings of infant mortality: how the United States compares with Europe. NCHS Data Brief, no 23. Hyattsville, MD: National Center for Health Statistics; 2009. Available at: www.cdc.gov/nchs/data/databriefs/ db23.htm. Accessed September 19, 2011

32. Arias E. United States life tables by Hispanic origin. Vital Health Stat 2. 2010;(152): 1-33

33. National Center for Health Statistics. Vital Stats. Available at: www.cdc.gov/nchs/ VitalStats.htm. Accessed September 19, 2011

34. National Association for Public Health Statistics and Information Systems. Cooperative agreement for state vital statistics improvement. Available at: www.naphsis.org/ index.asp?bid=1021. Accessed September 19, 2011

35. National Center for Health Statistics. About the National Vital Statistics System. Available at: www.cdc.gov/nchs/nvss/about_nvss.htm. Accessed September 19, 2011 